\title{
Properties of mixed crystalline organic material prepared by zone levelling III. Vapour pressures of (trans- azobenzene + trans-stilbene)
}

\author{
J. A. BOUWSTRA, H. A. J. OONK, J. G. BLOK, \\ and C. G. DE KRUIF \\ Chemical Thermodynamics Group, State University of Utrecht. \\ Padualaan 8, 3508 TB Utrecht, The Netherlands
}

(Received 8 August 1983)

\begin{abstract}
The solid-vapour equilibrium of mixed crystals: $\left\{(1-x)\right.$ trans- $\mathrm{C}_{6} \mathrm{H}_{5} \mathrm{~N}: \mathrm{NC}_{6} \mathrm{H}_{5}+(x)$ trans$\left.\mathrm{C}_{6} \mathrm{H}_{5} \mathrm{CH}: \mathrm{CHC}_{6} \mathrm{H}_{5}\right\}$, prepared by zone levelling, has been determined as a function of temperature and composition. Experimental vapour pressures range from $0.10 \mathrm{~Pa}$ to $12 \mathrm{~Pa}$ at temperatures from 298 to $365 \mathrm{~K}$. Assuming ideal-gas behaviour in this range, the excess molar Gibbs energy of the solid phase is about $500 x(1-x) \mathrm{J} \cdot \mathrm{mol}^{-1}$.
\end{abstract}

\section{Introduction}

Homogeneous solid mixtures of organic substances can be obtained by the method of zone levelling. ${ }^{(1)}$ The melting properties and the vapour pressures of ( $p$-dichlorobenzene $+p$-dibromobenzene) were reported in parts ${ }^{(2)}$ and $\mathrm{II}^{\left({ }^{(3)}\right.}$ This paper reports vapour-pressure measurements on $\left\{(1-x)\right.$ trans $-\mathrm{C}_{6} \mathrm{H}_{5} \mathrm{~N}: \mathrm{NC}_{6} \mathrm{H}_{5}+$ (x)trans $\left.-\mathrm{C}_{6} \mathrm{H}_{5} \mathrm{CH}: \mathrm{CHC}_{6} \mathrm{H}_{5}\right\}$ (cr). The experimental vapour pressures are used to determine the extent to which the solid mixtures deviate from ideality.

\section{Materials}

Trans-stilbene, purified by counter-current crystallization, was supplied by the Physical Chemical Laboratory of T.N.O., Zeist, the Netherlands. The purity of the sample, established by g.l.c., was $(99.95 \pm 0.05)$ moles per cent. ${ }^{(4)}$ Trans-azobenzene was first purified by slow vacuum sublimation, which was followed by zone refining: 80 passes with a Nonius combined normal freezing and multi-stage zone-refining apparatus working at a travel speed of $0.2 \mathrm{~cm} \cdot \mathrm{s}^{-1}$. The purity, established by adiabatic calorimetry, was better than 99.5 moles per cent. ${ }^{(5)}$

The mixed crystalline material was prepared by means of zone levelling. A detailed description of the appratus and the underlying theory are given elsewhere. ${ }^{(6)}$ Twenty passes were applied, the speed being $2 \times 10^{-7} \mathrm{~m} \cdot \mathrm{s}^{-1}$. Unfortunately, transstilbene showed some decomposition at the higher temperatures. For this reason it 
was possible to prepare homogeneous mixed crystals which contain only up to 70 moles per cent of trans-stilbene. The final composition along the ingot was determined by g.l.c. at the Laboratory of Chemical Animal Physiology. State University of Utrecht.

\section{Experimental}

The glass sample cell was connected to two different sensor heads (model 94AH, MKS Instruments Inc.), one for measurements up to $133 \mathrm{~Pa}$ and the other for measurements up to $133 \mathrm{kPa}$. The temperature of the sample cell could be measured to within $0.01 \mathrm{~K}$ with a platinum resistance thermometer. The whole apparatus was

TABLE 1. Experimental vapour pressures of trans-stilbene (solid) and trans-azobenzene (solid and liquid) and residuals of equation (1)

\begin{tabular}{|c|c|c|c|c|c|c|c|c|c|c|c|}
\hline$T$ & $p$ & $100 \delta p$ & $T$ & $p$ & $100 \delta p$ & $T$ & $p$ & $100 \delta p$ & $T$ & $p$ & $100 \delta p$ \\
\hline$\overline{\mathrm{K}}$ & $\overline{\mathrm{Pa}}$ & $p$ & $\overline{\mathrm{K}}$ & $\overline{\mathrm{Pa}}$ & $p$ & $\overline{\mathrm{K}}$ & $\overline{\mathrm{Pa}}$ & $p$ & $\overline{\mathrm{K}}$ & $\overline{\mathrm{Pa}}$ & $p$ \\
\hline \multicolumn{12}{|c|}{$\begin{array}{c}\text { trans-Stilbene } \\
\text { static method (series I) }\end{array}$} \\
\hline 342.32 & 1.43 & -2.27 & 348.88 & 2.81 & 0.24 & 359.50 & 7.71 & 0.08 & \multirow[t]{4}{*}{364.50} & \multirow[t]{4}{*}{12.20} & \multirow[t]{4}{*}{0.68} \\
\hline 344.40 & 1.83 & 1.35 & 350.03 & 3.10 & -1.46 & 359.53 & 7.74 & 0.23 & & & \\
\hline 345.35 & 1.94 & -2.21 & 353.21 & 4.34 & 1.46 & 359.66 & 7.90 & 1.05 & & & \\
\hline 347.33 & 2.39 & -1.35 & 354.94 & 5.07 & 0.65 & 363.58 & 11.22 & 0.61 & & & \\
\hline \multicolumn{12}{|c|}{ static method (series II) } \\
\hline 342.60 & 1.44 & -4.21 & 348.98 & 2.80 & -1.65 & 353.54 & 4.39 & -0.52 & 360.50 & 8.47 & 0.36 \\
\hline 344.67 & 1.80 & -3.13 & 349.01 & 2.83 & -0.68 & 356.51 & 5.84 & 0.15 & 362.89 & 10.57 & 0.73 \\
\hline 346.85 & 2.25 & -2.42 & 351.42 & 3.55 & 1.35 & 358.19 & 6.86 & 0.52 & & & \\
\hline \multicolumn{12}{|c|}{ torsion mass-loss effusion } \\
\hline 318.12 & 0.10 & -2.87 & 329.95 & 0.40 & 0.97 & 334.98 & 0.70 & 2.59 & 338.26 & 1.00 & 3.73 \\
\hline 323.93 & 0.20 & -1.02 & 331.94 & 0.50 & 1.58 & 336.20 & 0.8 & 3.02 & & & \\
\hline 327.42 & 0.30 & 0.18 & 333.58 & 0.60 & 2.13 & 337.29 & 0.90 & 3.33 & & & \\
\hline \multicolumn{12}{|c|}{$\begin{array}{l}\text { Azobenzene (solid) } \\
\text { static method }\end{array}$} \\
\hline 313.50 & 0.72 & 6.47 & 321.20 & 1.57 & -1.54 & 330.16 & 4.06 & -0.63 & 336.93 & 7.98 & -0.50 \\
\hline 314.23 & 0.68 & -7.28 & 323.85 & 2.11 & -0.25 & 332 & 5.0 & 0.05 & 339.10 & 10.05 & 1.57 \\
\hline 317.51 & 1.06 & -0.38 & 325.97 & 2.64 & -0.46 & 334.80 & 6.5 & 0.26 & 339.26 & 10.00 & -0.48 \\
\hline 318.51 & 1.12 & -5.60 & 327.93 & 3.22 & -0.75 & 335.46 & 7.08 & 1.94 & 340.95 & 11.73 & -0.66 \\
\hline \multicolumn{12}{|c|}{ torsion mass-loss effusion } \\
\hline 297.85 & 0.10 & -1.10 & 308.97 & 0.40 & 0.49 & 313.70 & 0.70 & 1.43 & 316.79 & 1.00 & 2.15 \\
\hline 303.31 & 0.20 & -0.47 & 310.84 & 0.50 & 0.83 & 314.85 & 0.80 & 1.69 & & & \\
\hline 306.59 & 0.30 & 0.12 & 312.38 & 0.60 & 1.19 & 315.87 & 0.90 & 1.94 & & & \\
\hline \multicolumn{12}{|c|}{$\begin{array}{l}\text { Azobenzene (liquid) } \\
\text { static method }\end{array}$} \\
\hline & & -0.36 & 349.82 & 21.82 & -0.51 & 352.33 & 26.18 & 0.76 & 358.02 & 37.86 & 0.16 \\
\hline 345.28 & 16.08 & -0.14 & 349.81 & 22.14 & 1.00 & 358.05 & 37.79 & -0.26 & 362.91 & 51.50 & -0.38 \\
\hline 347.74 & 18.98 & -0.26 & & & & & & & & & \\
\hline
\end{tabular}


mounted in an air thermostat. Precautions were taken to reduce thermal leakage and ambient-temperature influences as much as possible. A detailed description of the apparatus is to be found. ${ }^{(7)}$

Measurements were made as follows. About $1 \mathrm{~g}$ of powdered substance was inserted into the sample cell. For a pure substance the thermostat was set at the highest measuring temperature. Some cycles of alternate pumping and measuring followed until the pressure became constant. These cycles were made so as to suppress any effects arising from desorption of gases from the sample and the walls. For homogeneous mixed crystals the measurements were started at the lowest temperature so as to avoid composition variations of the solid material, although the measurements were corrected for these variations. The vapour pressures were corrected for thermal transpiration according to Bennett and Tompkins. ${ }^{(8)}$

The vapour pressures of the pure substances were also measured by means of a simultaneous torsion and mass-loss effusion method. The pressure range for this method is lower than that for the static method. A detailed description of the torsion and mass-loss effusion technique and the experimental set-up can he found. ${ }^{(9)}$

\section{Results and discussion}

\section{PURE SUBSTANCES}

The vapour pressures of the pure substances in the solid state were measured both by the dynamic and by the static method. The temperature ranges for trans-stilbene were 298 to $317 \mathrm{~K}$ for the dynamic method and 313 to $341 \mathrm{~K}$ for the static method. For trans-azobenzene the temperature ranges were 318 to $339 \mathrm{~K}$ and 342 to $365 \mathrm{~K}$ for the dynamic and static method, respectively.

So as to obtain one overall function over a large temperature range the experimental results of the two methods were combined. These results, given in table 1 , can be represented by the equation: ${ }^{(10)}$

$$
R \ln \left(p / p^{\circ}\right)=-\left\{\Delta_{\mathrm{s}}^{\mathrm{g}} G_{\mathrm{m}}^{\circ}(\theta) / \theta\right\}+\Delta_{\mathrm{s}}^{\mathrm{g}} H_{\mathrm{m}}^{\circ}(\theta)\left(\theta^{-1}-T^{-1}\right)+\Delta_{\mathrm{s}}^{\mathrm{g}} C_{p, \mathrm{~m}}^{\circ}\{(\theta / T)-1+\ln (T / \theta)\},
$$

where $p$ stands for the reference vapour pressure $(1 \mathrm{~Pa})$ and $\theta$ for the reference temperature. The $\Delta_{\mathrm{s}}^{\mathrm{g}} G_{\mathrm{m}}^{\circ}(\theta), \Delta_{\mathrm{s}}^{\mathrm{g}} H_{\mathrm{m}}^{\circ}(\theta)$, and $\Delta_{\mathrm{s}}^{\mathrm{g}} C_{p, \mathrm{~m}}^{\circ}$ values are given in table 2 .

For trans-azobenzene, vapour pressures of the liquid were also measured. From the solid vapour-pressure line and from the liquid vapour-pressure line, the melting

TABLE 2. Parameters of equation (1): molar Gibbs energy, molar enthalpy, and molar heat capacity of sublimation

\begin{tabular}{|c|c|c|c|c|}
\hline & $\theta$ & $\Delta_{s}^{\mathrm{g}} G_{m}^{\prime}(\theta)$ & $\Delta_{\mathrm{s}}^{\mathrm{g}} H_{\mathrm{m}}(\theta)$ & $\Delta_{s}^{\mathrm{g}} C_{p, m}^{r}$ \\
\hline & $\overrightarrow{\mathrm{K}}$ & $\overline{\mathrm{J} \cdot \mathrm{mol}^{-1}}$ & $\overline{\mathrm{kJ}} \cdot \mathrm{mol}^{-1}$ & $\mathrm{~J} \cdot \mathrm{K}^{-1} \cdot \mathrm{mol}^{-1}$ \\
\hline $\begin{array}{l}\text { trans- } \mathrm{C}_{6} \mathrm{H}_{5} \mathrm{~N}: \mathrm{NC}_{6} \mathrm{H}_{5}(\mathrm{~s}) \\
\text { trans- } \mathrm{C}_{6} \mathrm{H}_{5} \mathrm{~N}: \mathrm{NC}_{6} \mathrm{H}_{5}(\mathrm{l}) \\
\text { trans }-\mathrm{C}_{6} \mathrm{H}_{5} \mathrm{CH}: \mathrm{CHC}_{6} \mathrm{H}_{5}(\mathrm{~s})\end{array}$ & $\begin{array}{l}335 \\
341 \\
335\end{array}$ & $\begin{array}{r}-5272 \pm 22 \\
-7020 \pm 11 \\
1060 \pm 14\end{array}$ & $\begin{array}{l}92.1 \pm 0.9 \\
69.1 \pm 0.3^{a} \\
99.2 \pm 0.4\end{array}$ & $\begin{array}{l}-69 \pm 61^{\circ} \\
-19 \pm 41^{\circ}\end{array}$ \\
\hline
\end{tabular}

"Mean value for the experimental temperature range. 
temperature and the molar enthalpy of fusion are $T^{\mathrm{s}+1}=(341.0 \pm 0.3) \mathrm{K}$, $\Delta_{\mathrm{s}}^{1} H_{\mathrm{m}}^{\circ}=(22.6 \pm 0.4) \mathrm{kJ} \cdot \mathrm{mol}^{-1}$; these values agree well with those obtained by adiabatic calorimetry: ${ }^{(5)} T^{\mathrm{s}+1}=(341.03 \pm 0.01) \mathrm{K}$ and $\Delta_{\mathrm{s}}^{\mathrm{l}} H_{\mathrm{m}}^{\circ}-(22.52 \pm 0.02) \mathrm{kJ} \cdot \mathrm{mol}^{-1}$.

\section{ZONE-LEVELLED SAMPLES}

Vapour-pressure measurements were made on six zone-levelled samples using the static method.

The vapour pressures were corrected for the change in composition of the solid phase. The corrections were performed in such a way that the composition change of the solid phase calculated from the amount of vapour which was pumped off

TABLE 3. Experimental vapour pressures and least-squares parameters of equation (2) with $\gamma$ as inserted value and the reference temperature $\theta=335 \mathrm{~K}$

\begin{tabular}{|c|c|c|c|c|c|c|c|c|c|}
\hline & \multirow[b]{2}{*}{$T / \mathrm{K}$} & \multicolumn{2}{|c|}{$p / \mathrm{Pa}$} & \multicolumn{4}{|c|}{$p / \mathrm{Pa}$} & \multicolumn{2}{|c|}{$p / \mathrm{Pa}$} \\
\hline & & expt & calc. & $T / \mathrm{K}$ & expt & calc. & $T / \mathrm{K}$ & $\operatorname{expt}$ & calc. \\
\hline & \multicolumn{3}{|c|}{$\alpha=-(4895.2 \pm 9.3) \mathrm{J} \cdot \mathrm{mol}^{-1}$} & \multicolumn{6}{|c|}{$\beta=(94.8 \pm 0.3) \mathrm{kJ} \cdot \mathrm{mol}^{-1} \quad \gamma=-62 \mathrm{~J} \cdot \mathrm{K}^{-1} \cdot \mathrm{mol}^{-1}$} \\
\hline \multirow[t]{4}{*}{0.135} & 320.03 & 1.16 & 1.17 & 326.60 & 2.43 & 2.41 & 333.57 & 5.00 & 5.00 \\
\hline & 322.60 & 1.54 & 1.56 & 330.32 & 3.80 & 3.79 & 336.56 & 6.78 & 6.79 \\
\hline & 324.36 & 1.89 & 1.89 & 330.87 & 3.66 & 3.57 & 339.56 & 9.09 & 9.16 \\
\hline & \multicolumn{3}{|c|}{$\alpha--\left(4509.4\lfloor 3.2) \mathrm{J} \cdot \mathrm{mol}^{-1}\right.$} & \multicolumn{6}{|c|}{$\beta=(93.4 \perp 1.0) \mathrm{kJ} \cdot \mathrm{mol}^{-1} \quad \gamma=-56 \mathrm{~J} \cdot \mathrm{K}^{-1} \cdot \mathrm{mol}^{-1}$} \\
\hline \multirow[t]{5}{*}{0.262} & 319.71 & 1.013 & 1.007 & 330.80 & 3.277 & 3.295 & 343.44 & 10.152 & 11.486 \\
\hline & 322.23 & 1.328 & 1.338 & 334.05 & 4.590 & 4.589 & 346.75 & 15.689 & 15.680 \\
\hline & 324.91 & 1.769 & 1.777 & 337.28 & 6.340 & 6.333 & & & \\
\hline & 328.21 & 2.514 & 2.517 & 340.03 & 8.285 & 8.285 & & & \\
\hline & \multicolumn{3}{|c|}{$\alpha=-(4219.5 \pm 20.6) \mathrm{J} \cdot \mathrm{mol}^{-1}$} & \multicolumn{6}{|c|}{$\beta=(92.8 \pm 0.9) \mathrm{kJ} \cdot \mathrm{mol}^{-1} \quad \gamma=-51 \mathbf{J} \cdot \mathbf{K}^{-1} \cdot \mathrm{mol}^{-1}$} \\
\hline \multirow[t]{6}{*}{0.359} & 322.44 & 1.231 & 1.237 & 337.43 & 5.818 & 5.782 & 339.73 & 7.203 & 7.230 \\
\hline & 324.84 & 1.536 & 1.600 & 324.52 & 1.623 & 1.547 & 340.15 & 7.564 & 7.526 \\
\hline & 327.64 & 2.064 & 2.148 & 327.72 & 2.226 & 2.167 & 343.66 & 10.430 & 10.509 \\
\hline & 331.19 & 3.087 & 3.100 & 330.39 & 2.887 & 2.856 & & & \\
\hline & 334.28 & 4.246 & 4.233 & 336.32 & 5.191 & 5.182 & & & \\
\hline & \multicolumn{3}{|c|}{$\alpha=-(3876.0 \pm 6.1) \mathrm{J} \cdot \mathrm{mol}^{-1}$} & \multicolumn{6}{|c|}{$\beta=(94.4 \pm 0.3) \mathrm{kJ} \cdot \mathrm{mol}^{-1} \quad \gamma=-47 \mathrm{~J} \cdot \mathrm{K}^{-1} \cdot \mathrm{mol}^{-1}$} \\
\hline \multirow[t]{4}{*}{0.450} & 324.29 & 1.323 & 1.309 & 331.36 & 2.986 & 3.001 & 341.63 & 7.774 & 7.750 \\
\hline & 326.85 & 1.702 & 1.723 & 335.00 & 4.024 & 4.022 & 344.05 & 9.791 & 9.792 \\
\hline & 329.78 & 2.356 & 2.351 & 337.92 & 5.404 & 5.389 & 346.57 & 12.425 & 12.434 \\
\hline & \multicolumn{3}{|c|}{$x=-(3397.5 \pm 4.9) \mathrm{J} \cdot \mathrm{mol}^{-1}$} & \multicolumn{6}{|c|}{$\beta=(94.6 \pm 0.3) \mathrm{kJ} \cdot \mathrm{mol}^{-1} \quad \gamma=-41 \mathrm{~J} \cdot \mathrm{K}^{-1} \cdot \mathrm{mol}^{-1}$} \\
\hline \multirow[t]{4}{*}{0.556} & 326.22 & 1.358 & 1.335 & 336.67 & 4.011 & 4.008 & 347.69 & 11.66 & 11.66 \\
\hline & 330.13 & 2.043 & 2.052 & 340.36 & 5.820 & 5.774 & 350.28 & 14.75 & 14.83 \\
\hline & 333.29 & 2.836 & 2.846 & 343.86 & 8.123 & 8.106 & & & \\
\hline & \multicolumn{3}{|c|}{$\alpha=-(2739.8 \pm 9.3) \mathrm{J} \cdot \mathrm{mol}^{-1}$} & \multicolumn{6}{|c|}{$\beta=(95.5 \pm 0.3) \mathrm{kJ} \cdot \mathrm{mol}^{-1} \quad y=-34 \mathrm{~J} \cdot \mathrm{K}^{-1} \cdot \mathrm{mol}^{-1}$} \\
\hline 0.698 & 325.05 & 0.946 & 0.935 & 336.35 & 3.013 & 3.068 & 348.50 & 10.036 & 10.051 \\
\hline & 327.49 & 1.224 & 1.217 & 339.40 & 4.178 & 4.168 & 351.95 & 13.906 & 13.858 \\
\hline & 330.60 & 1.688 & 1.694 & 342.44 & 5.585 & 5.623 & 353.38 & 16.057 & 16.815 \\
\hline & 334.07 & 2.431 & 2.431 & 345.69 & 7.634 & 7.703 & & & \\
\hline
\end{tabular}


during every (measuring and pumping) cycle was in agreement with the composition change of the solid material determined by g.l.c. It appeared that the change in composition, which was within 0.035 mole fraction, resulted in a total vapourpressure correction that varied between 0.1 per cent (at the lowest and first measuring temperature) and 5 per cent (at the highest and final measuring temperature). The vapour pressures corresponding to a solid mixture of given composition were represented by the equation:

$$
R \ln \left(p / p^{\circ}\right)=-\{\alpha(\theta) / \theta\}+\beta(\theta)\left(\theta^{-1}-T^{-1}\right)+\gamma\{(\theta / T)-1+\ln (T / \theta)\},
$$

in which a certain value was introduced for $\gamma$. As the compositions of the solid and vapour phase are not the same, and as they change in a different manner with temperature, the quantities $\alpha, \beta$, and $\gamma$ do not stand in a simple relation to $\Delta_{\mathrm{s}}^{\mathrm{g}} G_{\mathrm{m}}(\theta)$, $\Delta_{s}^{\mathrm{g}} H_{\mathrm{m}}(\theta)$, and $\Delta_{\mathrm{s}}^{\mathrm{g}} C_{p, \mathrm{~m}}(\theta)$, both states having the same composition. In spite of this we introduced for $\gamma$ the value: $\left\{(1-x) \Delta_{s}^{\mathrm{g}} C_{p, \mathrm{~m}, 1}^{0}+x \Delta_{\mathrm{s}}^{\mathrm{g}} C_{p, \mathrm{~m}, 2}^{\prime}\right\}$, where $\Delta_{\mathrm{s}}^{\mathrm{g}} C_{p, \mathrm{~m}, 1}^{0}$ stands for the difference in molar heat capacity of vapour and solid phase for transazobenzene, $\Delta C_{p, m, 2}^{\circ}$ stands for the difference in molar heat capacity of vapour and solid phase for trans-stilbene, and $x$ is the mole fraction of trans $-\mathrm{C}_{6} \mathrm{H}_{5} \mathrm{CH}: \mathrm{CHC}_{6} \mathrm{H}_{5}$ in the solid phase.

The $\alpha(\theta)$ and $\beta(\theta)$ values obtained at a reference temperature of $335 \mathrm{~K}$, together with $\gamma$ values and the corrected vapour pressures are given in table 3 . In figure 1 , in which $\ln \left(p / p^{\circ}\right)$ is plotted against $1 / T$, three horizontal cross-sections were made at three vapour pressures $(1,6$, and $11 \mathrm{~Pa})$. For each of the horizontal cross-sections the points of intersection with the vapour-pressure lines of the different samples were calculated. These intersections, i.e. the compositions and temperatures, represent the solidus points of three binary (vapour + solid) $(T, x)$ phase diagrams.

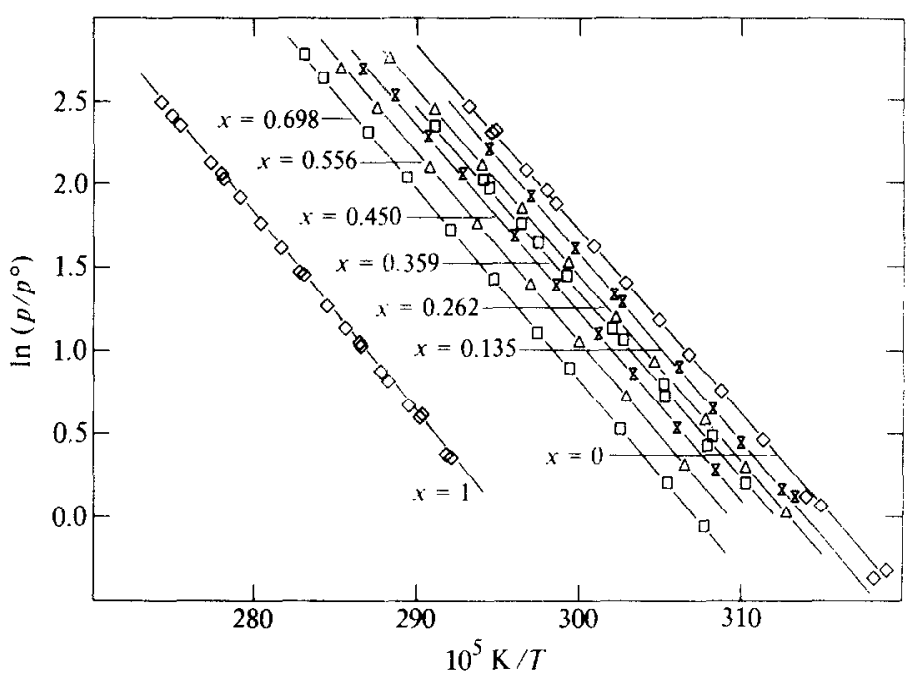

FIGURE 1. Static vapour-pressure measurements of pure substances and zone-levelled samples of $\left\{(1-x)\right.$ trans $-\mathrm{C}_{6} \mathrm{H}_{5} \mathrm{~N}: \mathrm{NC}_{6} \mathrm{H}_{5}+(x)$ trans $\left.-\mathrm{C}_{6} \mathrm{H}_{5} \mathrm{CH}: \mathrm{CHC}_{6} \mathrm{H}_{5}\right\} ;-$, calculated. 

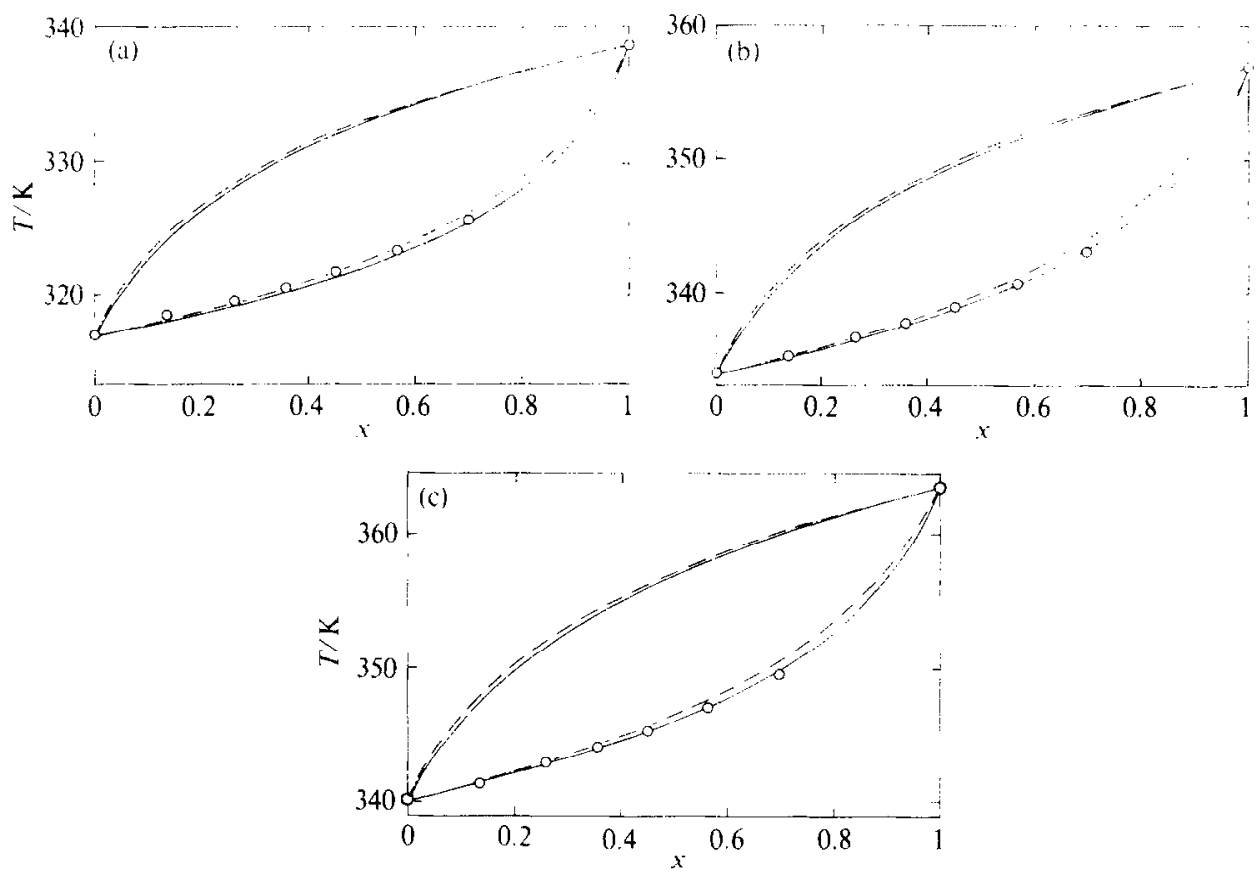

FIGURE 2. Plot of $T$ against $x$ for $\left\{(1-x)\right.$ trans $-\mathrm{C}_{6} \mathrm{H}_{5} \mathrm{~N}: \mathrm{NC}_{6} \mathrm{H}_{5}+(x)$ trans $\left.-\mathrm{C}_{6} \mathrm{H}_{5} \mathrm{CH}: \mathrm{CHC}_{6} \mathrm{H}_{5}\right\}$ at (a) $1 \mathrm{~Pa}$, (b) $6 \mathrm{~Pa}$, and (c) $11 \mathrm{~Pa} . \cdots$, ideal phase diagram; $G_{\mathrm{m}}^{k, \mathrm{~s}}=500 x(1-x) \mathrm{J} \cdot \mathrm{mol}^{-1}$.

The three $(T, x)$ phase diagrams are shown in figure 2. Using the properties of the pure components and assuming ideal behaviour in the vapour phase a number of phase-diagram calculations were made with varying excess molar Gibbs energy of the solid state. For the latter we used the simple expression: $G_{\mathrm{m}}^{\mathrm{E} . \mathrm{s}}(x)=A x(1-x)$. The best agreement between calculated solidus curves and experimental solidus points was obtained with $A=500 \mathrm{~J} \cdot \mathrm{mol}^{-1}$. The calculated phase diagrams corresponding to this numerical value are shown in figure 2.

In view of these calculations and taking into account the experimental uncertainties we assume that the expression: $G_{\mathrm{m}}^{\mathrm{E}, \mathrm{s}}=(500 \pm 300) x(1-x) \mathrm{J} \cdot \mathrm{mol}^{-1}$ gives a realistic estimate of the deviation from ideality in the temperature range 320 to $365 \mathrm{~K}$. To verify this finding we decided to make a thermodynamic assessment of the solid-liquid equilibrium. The solid-liquid phase diagram has been determined by Kofler and Brandstätter ${ }^{(1)}$ and by Vetter et al. ${ }^{(12)}$ The excess molar Gibbs energy of the solid state obtained from these phase diagrams with the LIQFIT method ${ }^{(13)}$ can be expressed as

and

$$
G_{\mathrm{m}}^{\mathrm{E}, \mathrm{s}}=x(1-x)\{(750 \pm 200)+(400 \pm 300)(1-2 x)\} \mathrm{J} \cdot \mathrm{mol}^{-1}
$$

respectively.

$$
G_{m}^{\mathrm{E}, \mathrm{s}}=x(1-x)\{(150 \pm 200)+(1150 \pm 300)(1-2 x)\} \mathrm{J} \cdot \mathrm{mol}^{-1}
$$


It can be concluded that solid mixtures of (trans-azobenzene + trans-stilbene) are nearly ideal, the deviation from ideality being only about $125 \mathrm{~J} \cdot \mathrm{mol}^{-1}$ for the $1-1$ mixture.

\section{REFERENCES}

I. Pfann, W. G. Zone melting. 2nd edition. Wiley: New York, London. 1959.

2. Genderen, A. C. G. van; Kruif, C. G. de; Oonk. H. A. J. Z. Phvs. Chem. Neue Folge 1977, 107, 167

3. Kruif, C. G. de; Genderen, A. C. G. van; Bink. J. C. W. G.; Oonk. H. A. J. J. Chem Thermodynamics 1981, 13, 457.

4. Personal communications with L. H. J. M. Schneiders of the Physical Chemical Laboratory of TNO. Zeist, The Netherlands.

5. Miltenburg, J. C. van; Bouwstra, J. A. J. Chem. Thermodynamics 1984, 16, 61 .

6. Kolkert, W. J. Growth of homogeneous organic mixed crustals by repeated-pass zone levelling. Thesis. Utrecht, 1974.

7. Kruif, C. G. de: Kuipers, T.: Miltenburg, J. C. van: Schaake, R. C. F.: Stevens, G. I. Chem. Thermodynamics 1981, 13, 1081.

8. Bennett, M. J.: Tompkins, F. C. Trans. Faraday Soc. 1957, 53, 185.

9. Kruif, C. G. de; Ginkel, C. H. D. van. J. Chem. Thermodynamics 1977, 9.725.

10. Clark, E. C. W.; Glew, D. N. Trans. Faraday Soc. 1966, 62, 539.

11. Kofler, A.; Brandstätter, M. Z. Physik. Chem. 1942, 190, 341.

12. Vetter, H.: Rössler, S.; Schildknecht, H. Symposium über Zonenschmelzen und Kolonnenkristallisieren. Schildknecht, H.: editor. Kernforschungsansalt: Karlsruhe, Germany. 1963, p. 57.

13. Bouwstra, J. A.: Oonk, H. A. J. CALPHAD 1982, 6.11. 